MATEC Web of Conferences 40, 02005 (2016)

DOI: $10.1051 /$ matecconf/20164002005

(C) Owned by the authors, published by EDP Sciences, 2016

\title{
Examining the Relationship between Forces During Stereolithography 3D Printing and Geometric Parameters of the Model
}

\author{
Iaroslav Kovalenko ${ }^{1}$, Maryna Garan ${ }^{1}$, Andrii Shynkarenko ${ }^{1}$, Petr Zelený ${ }^{1}$ and Jiři Šafka ${ }^{1}$ \\ ${ }^{1}$ Technical University ofLiberec, Department of Manufacturing Systems and Automation, 46117 Liberec, Studentska 1402/2, Czech Republic
}

\begin{abstract}
In the case of stereolithography 3D printing technology, detaching formed model from the tank with photopolymer is a lengthy process. Forces, which appear during removing of solid photopolymer layerformed in stereolithography 3D DLP printer, can destroy the built model. In this article the detachment force is measured, obtained results arestatistically analyzed and relation between detach force, area of produced layer and thickness of the layer are verified. Linear dependence between detach force and built area is determined. On the other hand, relation between detach force and thickness of the layer is not confirmed.
\end{abstract}

\section{Introduction}

One of the main areas in $3 \mathrm{D}$ printing research nowadays is increasing the production speed of a model. In case of stereolithography, one of the most time-consuming processes is detaching of solid layer from the bottom of the tank.Some methods allow preventingstrongadhesion to the tank [1]. But mostly in classical stereolithography, its necessary remove the last layer of building material from the tank. This process is likely to causedamage to the whole model. Continuous measurement of this force brings the possibility of acceleration of detaching process. This force can be kept below the maximal level of breaking point to prevent model from damage.

\section{Stereolithography}

Stereolithography (SLA, SL) is a technology based on curing of photopolymer resin layer by layer using optical radiation in ultraviolet wavelength range. It was patented in 1986 by Charles (Chuck) W. Hull [2]. In our case UV power source is Digital Light Processing (DLP) projector. DLP 3D printing technology descends from the name of technology that was patented by Texas Instrument Inc. in 1986 by Dr. Larry Hornbeck [3]. The model of experimental printer is shown on Figure 1.

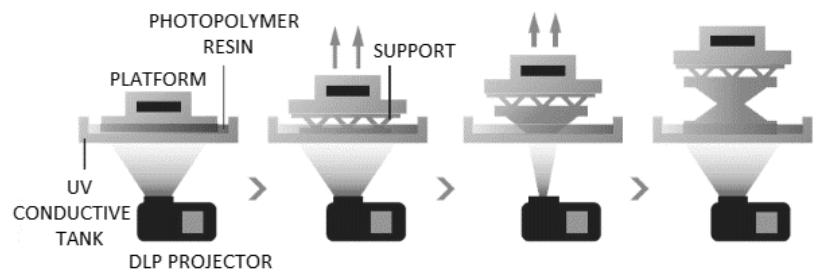

\section{Description of the experiment}

Experiment was made onthe DLP 3D printer, which is shown on Figure 2. This device was designed for testing of new detachment methods. Data projector is placed under the tank with photopolymer and illuminate bottom side of the tank. This solution allows economizing of building material, but on the other hand makes detaching process more complicated.

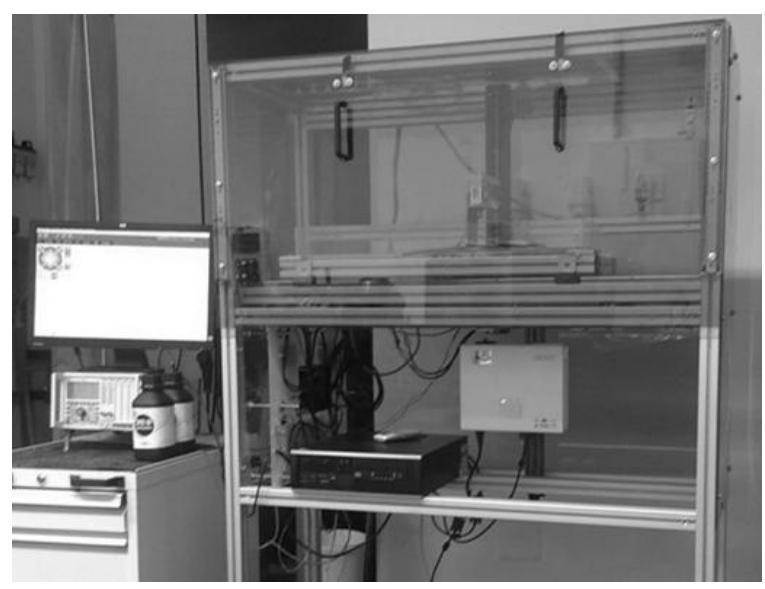

Figure 2. Experimental 3D DLP printer.

Platform can move in $\mathrm{Z}$ axe and has a minimal movement about $10 \mu \mathrm{m}$. It allows making thin layers from solidify resin.

A force sensor strain gagewas used. It was placed between platform brackets and building platform. Assembled experimental platform is shown on Figure 3.

Figure 1.The functional diagram of DLP 3D printer. 


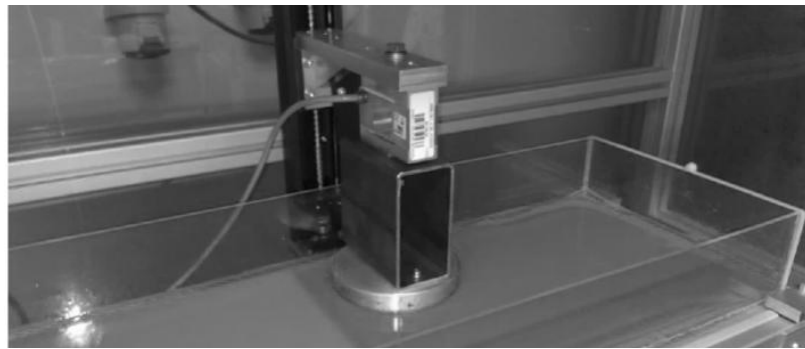

Figure 3.Building platform with strain gage sensor.

The forces are measured for the pyramidal CAD model, which is shown on Figure 4. It has different area of the stairs which are equal to $2500 \mathrm{~mm}^{2}, 1875 \mathrm{~mm}^{2}, 1250$ $\mathrm{mm}^{2}$ and $625 \mathrm{~mm}^{2}$.

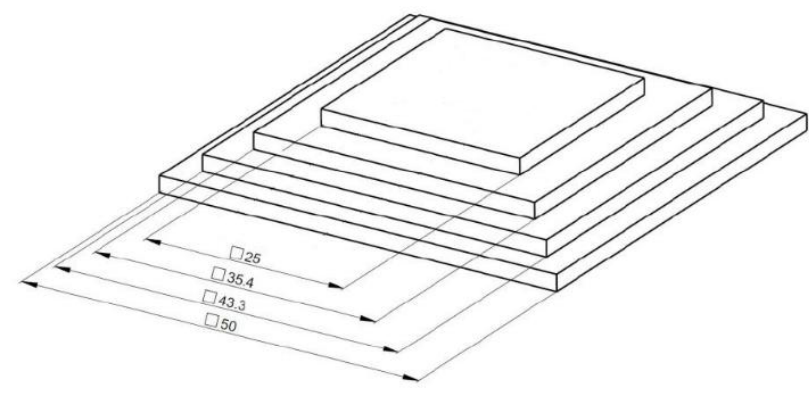

Figure 4. The printed model.

This model was sliced to layers with different thickness 25, 50 and $100 \mu \mathrm{m}$. Detaching forcesare measured ten times in the vertical directionfor each built area.

\section{Measurement results}

Data for statistical treatment were obtained from three models with different layer thickness. Results of measurements are shown in the Table 1-3. Also the primary statistical processing is represented.

Table 1. Measurement of detach force with constant layer thickness of $25 \mu \mathrm{m},[\mathrm{N}]$.

\begin{tabular}{|c|c|c|c|c|}
\hline \multirow{2}{*}{ Measurement } & \multicolumn{4}{|c|}{ Layer thickness is $25 \mu \mathrm{m}$} \\
\cline { 2 - 5 } & $\begin{array}{c}2500 \\
\mathrm{~mm}^{2}\end{array}$ & $\begin{array}{c}1875 \\
\mathrm{~mm}^{2}\end{array}$ & $\begin{array}{c}1250 \\
\mathrm{~mm}^{2}\end{array}$ & $\begin{array}{c}625 \\
\mathrm{~mm}^{2}\end{array}$ \\
\hline 1 & 44 & 34 & 26 & 20 \\
\hline 2 & 45 & 32 & 25 & 20 \\
\hline 3 & 42 & 34 & 26 & 17 \\
\hline 4 & 36 & 33 & 26 & 18 \\
\hline 5 & 35 & 34 & 25 & 18 \\
\hline 6 & 35 & 31 & 23 & 19 \\
\hline 7 & 36 & 32 & 24 & 17 \\
\hline 8 & 34 & 30 & 25 & 20 \\
\hline 9 & 35 & 30 & 24 & 19 \\
\hline $\begin{array}{c}\text { Arithmetical } \\
\text { mean, } \bar{y}\end{array}$ & 34.8571 & 32.1 & 24.9 & 18.6 \\
\hline Median, $\hat{y}$ & 35 & 32.5 & 25 & 18.5 \\
\hline $\begin{array}{c}\text { Relative } \\
\text { difference }\end{array}$ & 0.4098 & 1.2461 & 0.4016 & 0.5376 \\
\hline
\end{tabular}

Table 2. Measurement of detach force with constant layer thickness of $50 \mu \mathrm{m},[\mathrm{N}]$.

\begin{tabular}{|c|c|c|c|c|}
\hline \multirow{2}{*}{ Measurement } & \multicolumn{4}{|c|}{ Layer thickness is $50 \mu \mathrm{m}$} \\
\cline { 2 - 5 } & $\begin{array}{c}2500 \\
\mathrm{~mm}^{2}\end{array}$ & $\begin{array}{c}1875 \\
\mathrm{~mm}^{2}\end{array}$ & $\begin{array}{c}1250 \\
\mathrm{~mm}^{2}\end{array}$ & $\begin{array}{c}625 \\
\mathrm{~mm}^{2}\end{array}$ \\
\hline 1 & 47 & 27 & 23 & 17 \\
\hline 2 & 45 & 26 & 22 & 16 \\
\hline 3 & 46 & 27 & 22 & 16 \\
\hline 4 & 38 & 25 & 22 & 15 \\
\hline 5 & 36 & 26 & 21 & 16 \\
\hline 6 & 36 & 25 & 22 & 17 \\
\hline 7 & 35 & 27 & 23 & 16 \\
\hline 8 & 37 & 24 & 21 & 15 \\
\hline 9 & 36 & 25 & 21 & 13 \\
\hline 10 & 35 & 26 & 22 & 14 \\
\hline $\begin{array}{c}\text { Arithmetical } \\
\text { mean, } \bar{y}\end{array}$ & 36.1429 & 25.8 & 21.9 & 15.5 \\
\hline Median, $\hat{y}$ & 36 & 26 & 22 & 16 \\
\hline $\begin{array}{c}\text { Relative } \\
\text { difference }\end{array}$ & 0.3953 & 0.7752 & 0.4566 & 3.2258 \\
\hline
\end{tabular}

Table 3. Measurement of detach force with constant layer thickness of $100 \mu \mathrm{m},[\mathrm{N}]$.

\begin{tabular}{|c|c|c|c|c|}
\hline \multirow{2}{*}{ Measurement } & \multicolumn{4}{|c|}{ Layer thickness is $100 \mu \mathrm{m}$} \\
\cline { 2 - 5 } & $\begin{array}{c}2500 \\
\mathrm{~mm}^{2}\end{array}$ & $\begin{array}{c}1875 \\
\mathrm{~mm}^{2}\end{array}$ & $\begin{array}{c}1250 \\
\mathrm{~mm}^{2}\end{array}$ & $625 \mathrm{~mm}^{2}$ \\
\hline 1 & 37 & 24 & 19 & 12 \\
\hline 2 & 37 & 23 & 18 & 11 \\
\hline 3 & 36 & 23 & 19 & 10 \\
\hline 4 & 34 & 21 & 20 & 11 \\
\hline 5 & 34 & 22 & 18 & 11 \\
\hline 6 & 34 & 22 & 18 & 12 \\
\hline 7 & 32 & 23 & 17 & 9 \\
\hline 8 & 33 & 23 & 17 & 10 \\
\hline 9 & 34 & 22 & 18 & 10 \\
\hline 10 & 32 & 23 & 19 & 12 \\
\hline $\begin{array}{c}\text { Arithmetical } \\
\text { mean, } \bar{y}\end{array}$ & 33.2857 & 22.6 & 18.3 & 10.8 \\
\hline Median, $\hat{y}$ & 34 & 23 & 18 & 11 \\
\hline $\begin{array}{c}\text { Relative } \\
\text { difference }\end{array}$ & 2.1459 & 1.7699 & 1.6393 & 1.8519 \\
\hline
\end{tabular}

After the first analysis of obtained data we noticed, that first three values of take apart force in all models are significantly higher than the rest of values. These deviations came from the adhesion of platform to the bottom of the tank. These values can distort results of statistical treatment, that's why we discarded them from samples before processing.

For further analysis, we have to know, if data in measured samples are normally distributed. For this purpose, arithmetical means and medians in each sample are calculated (see Table 1-3). The relative differences between these values (see last rows in the Table 1-3) are calculated for each measured sample using this formula [4]:

$$
\frac{(\bar{y}-\hat{y})}{\bar{y}} \cdot 100 \%
$$

where

$\bar{y}$ is arithmetical mean,

$\hat{y}$ is median. 
For normally distributed data next equation effects:

$$
\bar{y}=\hat{y}
$$

For making an assumption, that data are normally distributed, relative difference between median and mean value has to be less than $10 \%$. As we can see, all values of relative differences satisfy this condition. Thus, we accept normal distribution for measured data.

\section{Statistical processing}

The goal of mentioned measurement was to check, if there is any linear dependence between obtained values:

- Detach force vs building area (Table 4),

- Detach force vs layer thickness (Table 5-6).

For this purpose, correlation coefficients between mentioned sets of data are calculated.

Table 4. Results of statistical treatment - part 1.

\begin{tabular}{|c|c|c|c|}
\hline Parameter Thickness & $25 \mu \mathrm{m}$ & $50 \mu \mathrm{m}$ & $100 \mu \mathrm{m}$ \\
\hline Building area, $x$ & \multicolumn{3}{|c|}{$\left[\begin{array}{c}2500 \\
1875 \\
1250 \\
625\end{array}\right]$} \\
\hline $\begin{array}{c}\text { Arithmetic } \\
\text { mean of } x, \bar{x}\end{array}$ & \multicolumn{3}{|c|}{1562.5000} \\
\hline Unstick force, $y$ & {$\left[\begin{array}{c}34.86 \\
32.1 \\
24.9 \\
18.6\end{array}\right]$} & {$\left[\begin{array}{c}36.14 \\
25.8 \\
21.9 \\
15.5\end{array}\right]$} & {$\left[\begin{array}{c}33.29 \\
22.6 \\
18.3 \\
10.8\end{array}\right]$} \\
\hline $\begin{array}{c}\text { Arithmetic } \\
\text { mean of } y, \bar{y}\end{array}$ & 27.6150 & 24.8350 & 21.2475 \\
\hline $\begin{array}{c}\text { Sample standard } \\
\text { deviation of } x \text {, } \\
S_{x}\end{array}$ & \multicolumn{3}{|c|}{698.7712} \\
\hline $\begin{array}{c}\text { Sample standard } \\
\text { deviation of } y \text {, } \\
S_{y} \\
\end{array}$ & 6.3491 & 7.4915 & 8.1346 \\
\hline $\begin{array}{c}\text { Covariance of } \\
\text { variables } x \text { and } \\
y, C_{x, y}\end{array}$ & 4373.4375 & 5142.1875 & 5607.0313 \\
\hline $\begin{array}{l}\text { Sample Pearson } \\
\text { correlation } \\
\text { coefficient, } r \\
\end{array}$ & 0.9858 & 0.9823 & 0.9864 \\
\hline Test statistics, $T$ & 8.2911 & 7.4161 & 8.4922 \\
\hline $\begin{array}{c}\text { Quantile of } \\
\text { Student's t- } \\
\text { distribution } \\
t_{2}(0.975)\end{array}$ & \multicolumn{3}{|c|}{4.303} \\
\hline
\end{tabular}

Table 5. Results of statistical treatment - part 2.

\begin{tabular}{|c|c|c|}
\hline Parameter $\quad$ Area & $2500 \mathrm{~mm}^{2}$ & $1875 \mathrm{~mm}^{2}$ \\
\hline Layer thickness, $x$ & \multicolumn{2}{|c|}{$\left[\begin{array}{c}25 \\
50 \\
100\end{array}\right]$} \\
\hline Arithmetic mean of $x, \bar{x}$ & \multicolumn{2}{|c|}{58.3333} \\
\hline
\end{tabular}

\begin{tabular}{|c|c|c|}
\hline Unstick force, $y$ & {$\left[\begin{array}{l}34.86 \\
36.14 \\
33.29\end{array}\right]$} & {$\left[\begin{array}{l}32.1 \\
25.8 \\
22.6\end{array}\right]$} \\
\hline Arithmetic mean of $y, \bar{y}$ & 34.7633 & 26.8333 \\
\hline $\begin{array}{c}\text { Sample standard deviation of } \\
x, S_{x}\end{array}$ & \multicolumn{2}{|c|}{31.1805} \\
\hline $\begin{array}{c}\text { Sample standard deviation of } \\
y, S_{y}\end{array}$ & 1.1655 & 3.9466 \\
\hline $\begin{array}{c}\text { Covariance of variables } x \text { and } \\
y, C_{x, y}\end{array}$ & -25.3611 & -114.4444 \\
\hline $\begin{array}{c}\text { Sample Pearson correlation } \\
\text { coefficient, } r\end{array}$ & -0.6979 & -0.9300 \\
\hline Test statistics, $T$ & -0.974 & -2.5305 \\
\hline $\begin{array}{c}\text { Quantile of Student's t- } \\
\text { distribution } t_{1}(0.975)\end{array}$ & 12.706 \\
\hline
\end{tabular}

Table 6. Results of statistical treatment - part 3.

\begin{tabular}{|c|c|c|}
\hline Area & $1250 \mathrm{~mm}^{2}$ & $625 \mathrm{~mm}^{2}$ \\
\hline Layer thickness, $x$ & \multicolumn{2}{|c|}{$\left[\begin{array}{l}25 \\
50 \\
100\end{array}\right]$} \\
\hline Arithmetic mean of $x, \bar{x}$ & \multicolumn{2}{|c|}{58.3333} \\
\hline Unstick force, $y$ & {$\left[\begin{array}{l}24.9 \\
21.9 \\
18.3\end{array}\right]$} & {$\left[\begin{array}{l}18.6 \\
15.5 \\
10.8\end{array}\right]$} \\
\hline $\begin{array}{c}\text { Arithmetic mean of } y, \bar{y} \\
x, S_{x}\end{array}$ & 21.7 & 14.9667 \\
\hline $\begin{array}{c}\text { Sample standard deviation of } \\
y, S_{y}\end{array}$ & 2.6981 & 3.2066 \\
\hline $\begin{array}{c}\text { Sample standard deviation of } \\
y, C_{x, y}\end{array}$ & -83.3333 & -99.7222 \\
\hline $\begin{array}{c}\text { Covariance of variables } x \text { and } \\
\text { coefficient, } r\end{array}$ & -0.9905 & -0.9974 \\
\hline $\begin{array}{c}\text { Sample Pearson correlation } \\
\text { Test statistics, } T\end{array}$ & -7.2169 & -13.8179 \\
\hline $\begin{array}{c}|c| \\
\text { Quantile of Student's t- } \\
\text { distribution } t_{2}(0.975)\end{array}$ & \multicolumn{2}{|c|}{12.706} \\
\hline
\end{tabular}

Since normality of measured samples was approved, we can use Pearson's correlation coefficient for testing of dependency between them. Sample Pearson's correlation coefficient can be found as follows [5]:

$$
r_{x, y}=\frac{C_{x, y}}{S_{x} \cdot S_{y}}
$$

where

$S_{x} \quad$ is sample standard deviation of $\mathrm{x}$,

$S_{y}$ is sample standard deviation of $\mathrm{y}$,

$C_{x, y}$ is covariance of variables $\mathrm{x}$ and $\mathrm{y}$.

$$
\begin{aligned}
& S_{x}=\sqrt{\frac{1}{n-1} \cdot \sum_{i=1}^{n}\left(x_{i}-\bar{x}\right)^{2}} \\
& S_{y}=\sqrt{\frac{1}{n-1} \cdot \sum_{i=1}^{n}\left(y_{i}-\bar{y}\right)^{2}}
\end{aligned}
$$




$$
C_{x, y}=\frac{1}{n-1} \cdot \sum_{i=1}^{n}\left(x_{i}-\bar{x}\right) \cdot\left(y_{i}-\bar{y}\right)
$$

For making a conclusion about linear dependence we should verify significance of correlation coefficientfor each couple of obtained samples. Test statistics looks as follows:

$$
T=r \cdot \sqrt{\frac{n-2}{1-r^{2}}}
$$

This value is compared to quantile of Student's tdistribution with degrees of freedom (n-2). If following condition is fulfilled, then correlation coefficient is significant and linear dependence between investigated values can be stated:

$$
|T| \geq t_{n-2}\left(1-\frac{\alpha}{2}\right)
$$

where

$$
\alpha=0.05 \quad \text { (significance level). }
$$

Since condition (8) is fulfilled for all samples in Table 5 , linear dependence between detach force and built area is confirmed. Thus, linear regression model can be applied on obtained data.

Using the least-squares method, parameters of approximating line can be found as follows [6]:

$$
\begin{gathered}
\widehat{\beta_{1}}=\frac{\sum_{i=1}^{n}\left(x_{i}-\bar{x}\right)\left(y_{i}-\bar{y}\right)}{\sum_{i=1}^{n}(x-\bar{x})^{2}} \\
\widehat{\beta_{0}}=\bar{y}-\widehat{\beta_{1}} \cdot \bar{x}
\end{gathered}
$$

Thus, approximating line will look like:

$$
y(x)=\widehat{\beta_{0}}+\widehat{\beta_{1}} \cdot x
$$

Regression models, which fit obtained data are shown on the Figure 5.
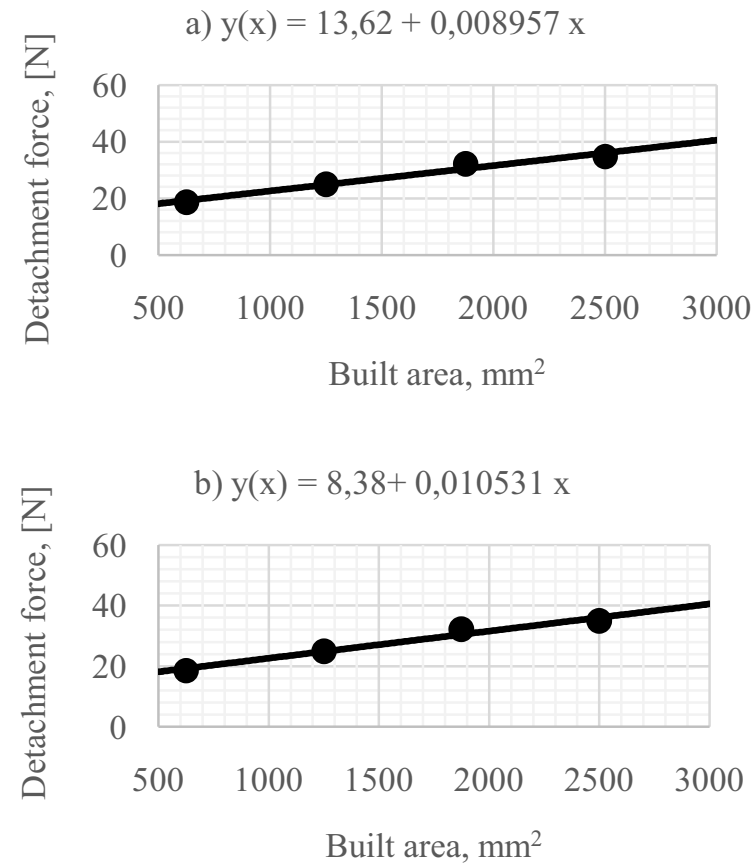

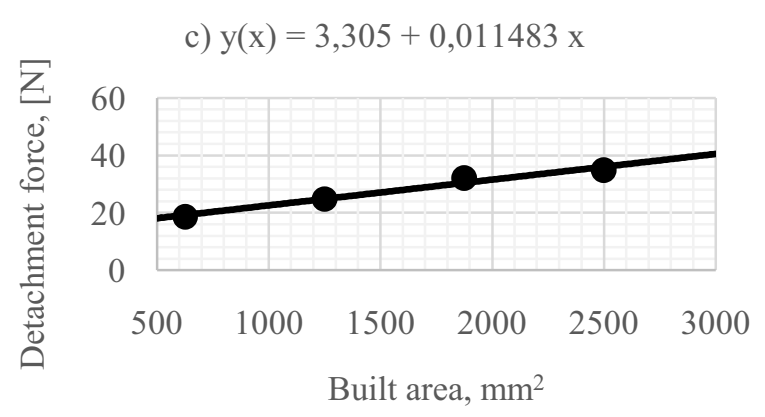

Figure 5. Regression models for different layer thickness a) 25 $\mu \mathrm{m}$; b) $50 \mu \mathrm{m}$; c) $100 \mu \mathrm{m}$.

\section{Conclusion}

The first task of this research was to check linear dependence between detach force and built area (Table 4). This dependence is confirmed and appropriate linear regression models are derived.

The second task was to check linear dependence between detach force and layer thickness (Table 5-6). Condition is fulfilled just for the last sample, linear dependence is not approved for rest of the samples. But since most of values of Pearson's correlation coefficient are very close to unity, we can make a conclusion, that measured samples do not contain enough measurements for approving the linear dependence.

\section{Acknowledgement}

The research reported in this paper was supported by targeted support for specific university research within the student grant competition TUL (Project 21071 Development and prototype production of compact DLP $3 \mathrm{D}$ printer).

\section{References}

1. J.R. Tumbleston, D. Shirvanyants, N. Ermoshkin, R. Janusziewicz, A.R. Johnson, D. Kelly, K. Chen, R. Pinschmidt, J.P Rolland, A. Ermoshkin, E. T.Samulski, J.M. DeSimone, Science, 347, 1349-1352, (2015)

2. L.J. Hornbeck, V. Alstyne, U.S. Patent, 4615595, (1986)

3. C.W. Hull, U.S. Patent, 4575330, (1986)

4. J.O. Bennett, W.L. Briggs, Using and Understanding Mathematics: A Quantitative Reasoning Approach, (Pearson,2004)

5. W.J. DeCoursey, Statistics and Probability for Engineering Applications, (Newnes,2003)

6. R. Lyman Ott, M. Longnecker, An Introduction to Statistical Methods and Data Analysis, (Brooks/Cole, 2010) 